\title{
Seeing Difference: The Effect of Economic Disparity on Black Attitudes Toward Latinos
}

\section{Citation}

Gay, Claudine, 2006. Seeing difference: The effect of economic disparity on black attitudes toward Latinos. American Journal of Political Science 50, no. 4: 982-997.

\section{Published Version}

http://dx.doi.org/10.1111/j.1540-5907.2006.00228.x

\section{Permanent link}

http://nrs.harvard.edu/urn-3:HUL.InstRepos:3352700

\section{Terms of Use}

This article was downloaded from Harvard University's DASH repository, and is made available under the terms and conditions applicable to Other Posted Material, as set forth at http:// nrs.harvard.edu/urn-3:HUL.InstRepos:dash.current.terms-of-use\#LAA

\section{Share Your Story}

The Harvard community has made this article openly available.

Please share how this access benefits you. Submit a story.

Accessibility 


\title{
Seeing Difference: \\ The Effect of Economic Disparity on Black Attitudes Toward Latinos
}

\author{
Claudine Gay \\ Department of Political Science \\ Encina Hall (West), Rm. 100 \\ Stanford University 94305-6044 \\ cgay@stanford.edu \\ (650) 736-1222
}

\begin{abstract}
Rapid growth in the size of the Latino population has increased the ethnic diversity of urban neighborhoods, transforming the residential experiences of many black Americans. The competition for scarce resources is considered a central force in black-Latino relations and a source of anti-Latino sentiment among blacks. This paper examines how the level and the distribution of economic resources within diverse areas affect black attitudes toward Latinos. Drawing on a multilevel dataset of individual racial attitudes and neighborhood characteristics, the analysis reveals that the relative economic status of racial groups is an important influence on black attitudes. In environments where Latinos are economically advantaged relative to their black neighbors, blacks are more likely to harbor negative stereotypes about Latinos, to be reluctant to extend to Latinos the same policy benefits they themselves enjoy, and to view black and Latino economic and political interests as incompatible. While the results suggest that diversity without conflict is possible, they make clear that the prospects for inter-group comity depend on some resolution of blacks' economic insecurities.
\end{abstract}




\section{Acknowledgements}

For useful comments and criticisms the author thanks Chris Afendulis, Regina Branton, Andrea Campbell, Jack Citrin, Darren Davis, Zoltan Hajnal, Eric Juenke, Taeku Lee, Tali Mendelberg,

Irwin Morris, Eric Oliver, Deborah Schildkraut, Gary Segura, Lester Spence, Susan Welch, Cara Wong, and Janelle Wong; seminar participants at the Center for American Political Studies at Harvard University, the Institute for Governmental Studies at UC Berkeley, and the Woodrow Wilson International Center for Scholars; and three anonymous referees. Special thanks to Michael Dawson and Lynn Sanders for thoughtful feedback on earlier drafts.

\section{Keywords}

Public Opinion, Racial attitudes, Racial Hostility, Race, Ethnicity, Power Threat, Black, Latino 
Decades of immigration from Latin America have reshaped the social landscape of the United States. According to the 2000 U.S. Census, Latinos now constitute 13.4 percent of the nation's population, making them the largest racial or ethnic minority group in the country. Nowhere are these changes more visible than in America's major metropolitan areas, where the Latino population remains largely concentrated (Guzman 2001). And perhaps no community is more acutely aware of these changes than African Americans, who are more likely to share neighborhoods with Latinos than any other racial or ethnic group (Glaeser and Vigdor 2001; Logan 2001). After generations in which most African Americans lived in racial isolation, the movement of Latinos into traditionally black communities is transforming neighborhoods where African Americans were once the dominant social and political force (Camarillo 2004; Mohl 2003). Despite early optimism that the influx of new minority groups into urban centers would improve the prospects for coalition (e.g., Browning, Marshall, and Tabb 1984), black-Latino relations have tended toward conflict (Falcon 1988; Meier and Stewart 1991; Vaca 2004). Reports from numerous cities describe the feelings of distrust and hostility that prevail among African Americans, preventing them from making common cause with Latinos (Bobo and Massagli 2001; Bobo et al. 1994; Mindiola, Neimann, and Rodriguez 2002; but see Cummings and Lambert 1997). ${ }^{1}$ For black political elites, increasingly aware of the need for cooperation across racial and ethnic lines if African Americans are to advance their policy interests, the trend is disturbing: anti-Latino sentiment among the black mass public may undermine elite efforts to build black-Latino alliances, putting at risk the group's future political and economic status.

Scholars have yet to reach consensus on the source of the negative attitudes among blacks. However, most accounts of the conflict identify the competition over scarce resources as a central force in black-Latino relations (Alozie and Ramirez 1999; Falcon 1988; Johnson and 
Oliver 1989; Kaufmann 2003a; Mindiola, Niemann, and Rodriguez 2002; Mohl 2003; Vaca 2004; but see McClain and Karnig 1990; McClain 1993; McClain and Tauber 1998, 2001). Idealized notions of "natural" inter-group comity and mutual support collapse when confronted by a finite number of public and (low-skilled) private sector jobs; by the lack of educational resources to meet the needs of black children and Spanish-speaking Latino children; by a shortage of adequate and affordable housing; and by the desire among both groups for descriptive political representation on neighborhood councils, school boards, and in municipal government. Antagonism toward Latinos is believed to emerge, at least in part, from African Americans' fears of displacement or loss due to the advancement of an out-group competitor. The fear, as one African American described it, is that Latinos are "taking the food from black children" (quoted in Vaca 2003, 5).

The conceptualization of black-Latino conflict as being conditional on blacks' fears of material deprivation prompts the question of what factors can amplify or neutralize these fears of displacement. In addition to a variety of individual-level correlates, researchers have sought to link the environment in which blacks live to their levels of anxiety about and hostility toward other minority groups (Bobo and Hutchings 1996; Bobo and Johnson 2000; Cain, Citrin, and Wong 2000; Cummings and Lambert 1997; Oliver and Wong 2003; Sears et al. 1999). To date, the primary emphasis has been on the racial composition of the environment, with fears of black displacement purported to increase with the size of the Latino population in the area.

Notably absent from these discussions has been close attention to the economic environment as a factor contributing to fears of black displacement (but see Oliver and Wong 2003). Yet insofar as tensions between blacks and Latinos emanate from a clash of material interests and from feelings of material vulnerability, we might reasonably expect economic 
conditions to shape relations between the two groups. The level and the distribution of economic resources in an area have direct implications for the socio-economic well-being and future socioeconomic mobility of individuals. With the narrow emphasis on the relative size of groups, scholars have largely ignored the potential fears and anxieties generated by conditions of material scarcity and by disparities in the economic status, and not simply the size, of racial and ethnic groups.

With those issues in mind, I consider how black racial attitudes vary across economic environments. In this article, I distinguish between the effects associated with the material condition of neighborhoods and those associated with the material conditions of group life. Drawing on a multilevel dataset of individual racial attitudes and neighborhood characteristics, the analysis reveals that the relative economic status of racial groups is an important influence on black attitudes. In environments where Latinos are economically advantaged relative to their black neighbors, African Americans are not only more likely to harbor negative stereotypes about Latinos, they are also more reluctant to extend to Latinos the same policy benefits they themselves enjoy and less likely to see black and Latino political and economic interests as consonant. While the results suggest that diversity without conflict is possible, they make clear that the prospects for inter-group comity will depend on some resolution of blacks' economic insecurities. I elaborate on these political implications in the conclusion.

\section{Black-Latino Conflict in Context}

Scholarly efforts to identify the contextual determinants of anti-Latino sentiment among blacks have focused on racial environments and their role in activating the fears of displacement at the core of inter-group conflict. Informed by the vast literature on white racial animositywhere the most widely accepted theory argues that fears of displacement and, in turn, hostility 
rise in direct proportion to the size of the black population in the area (Blalock 1967; Branton and Jones 2005; Giles and Evans 1986; Glaser 1994; Oliver and Mendelberg 2000; Taylor 2000) — several studies have sought to establish the link between black attitudes and the size of the proximate Latino population. Scholars have offered competing expectations about the nature of this relationship, although most predict a dynamic comparable to what is observed among whites, with large Latino populations associated with more negative black attitudes (Bobo and Johnson 2000; Cummings and Lambert 1997). ${ }^{2}$ Repeated empirical tests, however, have failed to uncover a consistent and statistically significant relationship between black attitudes and Latino population size, suggesting that proximity to Latinos alone may have little direct effect on black animosity (Bobo and Johnson 2000; Cummings and Lambert 1997; Sears et al. 1999).

In emphasizing blacks' spatial proximity to Latinos, researchers often overlook the role of economic circumstances in promoting ethnic and racial antagonism (Oliver and Mendelberg 2000). While scholars routinely take into account individual economic status as a determinant of blacks' orientations toward Latinos, as well as perceptions of economic conditions (e.g., Cummings and Lambert 1997; Tedin and Murray 1994), there have been few direct efforts to establish how the objective economic characteristics of the individual's environment influence the material fears and anxieties that ultimately pit groups against one another. Much of the research linking economic conditions to black-Latino tensions has been limited to tightly focused case studies of particular conflicts (e.g., Johnson and Oliver 1989).

Oliver and Wong (2003) depart from this approach, drawing on survey data from several metropolitan areas to examine the contextual determinants of black antagonism. Although primarily concerned with the implications of neighborhood ethnic diversity, the authors also hypothesize that the deep sense of material vulnerability common to individuals in "low-status" 
environments may provoke out-group hostility. Empirical tests of the relationship between neighborhood socio-economic status and anti-Latino sentiment provide partial support for their hypothesis: blacks in low-status contexts are more likely to view Latinos as direct competitors for political and economic resources, but are not more likely to harbor negative stereotypes about the group. I build on this recent work with a more extensive look at multiple dimensions of the economic environment, and greater theoretical and empirical attention to how ethnic and economic contexts jointly conspire to amplify the fears underlying out-group hostility.

There are two aspects of the economic environment with the potential to affect how blacks respond to an increasingly diverse urban landscape: the material condition of neighborhoods and the material conditions of group life. Resources and opportunities are not distributed equally across neighborhoods: some residential areas enjoy better services, safer streets, more open space, and higher home values than others, with favorable implications for the social and economic security of community residents. The material condition of a neighborhood may be crucial in activating anti-Latino sentiment among blacks — both indirectly, through its effect on the level of inter-group competition, and directly, as residents contend with the stress of social and economic dislocation. In communities plagued by high levels of economic distress, the scarcity of public and private goods may intensify the competition for resources and, as a result, the antagonism directed at out-groups perceived as competitors. Where resources are more abundant and economic circumstances less fragile, competition may be less frequent and intense and, thus, animosity less pervasive. If black antagonism is rooted in the competition for resources and activated by threats to material well-being, then attitudes are likely to be most negative when black and Latino neighbors are forced to compete for dwindling resources in a distressed area. 
Material scarcity may provoke hostility among residents of impoverished neighborhoods even in the absence of actual inter-group competition. The link between economic stress and outgroup animosity may not depend on whether blacks reside among, or spatially separated from, Latinos. As demonstrated in research on the contextual determinants of white racial animosity, generic distrust of out-groups is part of a wider "constellation of negative psychological states"-including feelings of relative deprivation, anxiety, and alienation —experienced by individuals faced with economic adversity (Oliver and Mendelberg 2000). Ethnographic accounts of blacks in urban ghettos confirm this pattern, with researchers describing a worldview that includes a "tough, cynical attitude toward life, a deep suspicion of the motives of others, and a marked lack of trust in the goodwill or benevolent intentions of people and institutions" (Massey and Denton 1993, 172). Moreover, Gay (2004) finds that African Americans trapped in "low quality" neighborhoods, as defined by features such as abandoned housing and limited access to shopping and other services, tend to be deeply pessimistic about the extent to which race and racism limit their individual life chances as well as the socio-economic attainment of blacks as a group. This bleak worldview may well extend to a hardening of attitudes toward Latinos, a group whose growing national prominence makes it a salient target. In short, black antagonism may derive from and express a more general frustration with the stigma and stress of life in decaying neighborhoods.

These expectations lead to the following hypothesis about neighborhood material conditions: African Americans who live in economically distressed neighborhoods are more likely than African Americans in better neighborhoods to harbor negative attitudes toward Latinos (H1). 
The material condition of group life is a second aspect of the economic environment with the potential to affect black attitudes toward Latinos. The material condition of group lifewhether group members, on balance, are economically secure or insecure — depends on the access group members have to important socio-economic resources, including jobs, education, and housing. Just as resources and opportunities are not distributed equally across neighborhoods, resource disparities also exist within neighborhoods: some residents are bettereducated, more gainfully-employed, and wealthier than others. In diverse neighborhoods, there can be differences across racial and ethnic groups in the economic niches typically occupied by group members, with some groups commanding more resources and enjoying more economic security. A larger share of the economic pie both improves the life chances of group members and enhances their social and political influence in the community. Neighborhood institutions, from social clubs to churches, are likely to cater to the group best able to sustain them financially, or else will struggle to survive; neighborhood businesses, from barbershops to tacquerias, will reflect the tastes of the community's most reliable patrons, or be replaced by businesses that do; and local elected officials will attend to the constituents best able to reward their responsiveness (with campaign contributions and high voter turnout), or be unseated by new political entrepreneurs who will. An advantaged economic position within a community confers a host of benefits to in-group members, while potentially imposing costs and burdens on out-group members, across multiple domains of life.

Although prior research on inter-group relations has focused on the effects of one group resource, relative group size, to the neglect of others, an advantaged economic position is a critical resource likely to shape the beliefs and attitudes that groups hold about one another. Moreover, a group's economic position, because it manifests itself in tangible ways (e.g. more 
Spanish-language church services) and materially shapes the day-to-day life of a community, is arguably no less visible to neighborhood residents than a group's size. Where significant economic disparities exist, members of the disadvantaged group, fearing further displacement and loss of resources and influence, may harbor more hostility toward the economically dominant group in their community. Resource disparities also may contribute to acute status anxiety, which scholars have found heightens out-group animosity in general (Horowitz 1985). Thus, with respect to black-Latino relations, the status characteristics, and not simply the size, of the black and Latino populations may determine how African Americans respond to their Latino neighbors. The fear and anxiety generated by a Latino population with greater access to important socio-economic resources may activate black antagonism.

These expectations lead to the following hypothesis about inter-group economic disparity: African Americans who live in neighborhoods where the Latino population is economically advantaged relative to the black population are more likely than African Americans in neighborhoods where blacks are at least as well off as Latinos to harbor negative attitudes toward Latinos (H2).

\section{Measuring Material Conditions}

I test these propositions with data from the 1992-1993 Los Angeles Study of Urban Inequality (LASUI), a linked survey of households and employers in metropolitan LA. This analysis relies on the household survey component and the 1103 adult respondents who selfidentified as black. ${ }^{3}$ Metropolitan LA provides a useful setting for exploring the contextual determinants of anti-Latino sentiment among blacks. Not only does LA have a sizable Latino population (more than one-third of the total population at the time of the survey), but blacks and Latinos there are less residentially segregated from one another than in other cities (Frey and 
Farley 1996). The residential integration of LA's blacks and Latinos (mainly Mexican Americans) is a relatively recent phenomenon, and a visible example of economic and demographic trends now unfolding throughout the country. As Camarillo (2004) documents, as late as the 1970s blacks and Latinos, though numbering close to two million people, lived for the most part in separate sections of the metropolitan area. Spatial patterns began to change 30 years ago, in part set in motion by the migration of middle class blacks out of the central city. As African Americans who could afford to do so left historically black neighborhoods for adjacent suburbs, a rapidly growing Latino population moved into the low cost housing made available by their departure. Within 20 years, the poor and working-class black residents of many of LA's historic black neighborhoods were living next door to or near a large number of Latinos.

But while the residential integration of blacks and Latinos makes the LASUI useful for addressing the questions of interest here, the survey remains a sample of residents from only one metropolitan area and is not a representative national sample of blacks. As such, caution is required when interpreting and generalizing from the results uncovered in the analysis, mindful that features unique to other metropolitan (or rural) areas may influence how African Americans respond to growing diversity. I return to this issue in the conclusion.

The contextual unit of interest is the neighborhood, which I define by the census block group in which each respondent resides. ${ }^{4}$ (The median population of a block group is 1321 residents.) I supplement the individual-level survey data with census data on the racial and ethnic composition of block groups, and the socio-economic characteristics of block-group residents. I measure neighborhood ethnic composition by the proportion of block-group residents who are Latino and the proportion black (PROPORTION Latino, PROPORTION black). The median percents Latino and black for the black respondents from Los Angeles are 24 percent and 40 
percent, respectively. Ten percent of African Americans reside in block-groups that are more than one-half Latino, and nearly one-quarter in neighborhoods that are less than 6 percent African-American.

I assess the material conditions in neighborhoods with two socio-economic indicators: the proportion of adult residents with at least a high school education (PROPORTION high schooleducated) and the proportion of households below the federal poverty line (PROPORTION below poverty). ${ }^{5}$ Neighborhood educational composition is a widely used measure of socioeconomic context (e.g., Branton and Jones 2005; Oliver and Wong 2003). However, educational composition alone is not sufficient to test the hypotheses regarding material conditions. The need for multiple measures is particularly great when studying African Americans, whose ability to convert educational attainment into improved residential circumstances is constrained by a racially segregated housing market (Alba and Logan 1991). Because the residential returns to education are smaller for blacks, the majority of upwardly mobile African Americans reside in communities shown to have higher crime rates, fewer local services, and poorer prospects for economic growth than neighborhoods in which whites of comparable status reside (Alba, Logan, and Bellair 1994; Phelan and Schneider 1996). For African Americans, neighborhood educational composition alone may reveal little about material conditions. I supplement the education data with poverty statistics in order to provide a more complete picture of residential circumstances.

The 1103 black respondents in the LASUI reside in 170 different block groups. One hundred sixty-five (165) of these block groups are integrated, containing both black and Latino residents. For these integrated block groups, I assess the disparity in the economic resources commanded by each racial and ethnic group using comparative measures based on race- and 
ethnicity-specific educational attainment and levels of poverty. Black and Latino poverty are measured by the proportions of black and Latino-headed households, respectively, with incomes below the poverty line. Group educational attainment is measured similarly. From these four block-group level measures, I construct indicators of relative economic status by first calculating the difference between each race/ethnicity-specific census item, e.g. the difference between the black poverty rate and the Latino poverty rate. Figure 1 depicts the distribution of these difference scores across the 165 integrated block groups. ${ }^{6}$ The difference scores range from a negative minimum value, indicating a block group with a black economic advantage (i.e. when black poverty is less than Latino poverty, or black education exceeds Latino education), to a positive maximum value, indicating a Latino economic advantage.

\section{[FIGURE 1 ABOUT HERE]}

Rather than use the raw values, I disaggregated each difference score into two separate indicators: a continuous measure of the degree to which blacks are advantaged relative to Latinos (i.e. the absolute value of a negative difference score); and a continuous measure of the degree to which Latinos are advantaged relative to blacks. When Latino (black) economic status equals or exceeds black (Latino) status, the value of the first (second) measure is set to zero. The benefit of this specification over a single continuous difference score is that, in the subsequent regression analysis, it does not require the assumption of a monotonic relationship between economic disparity and racial attitudes. The effect of black economic advantage is not assumed to be the opposite of the effect of black disadvantage; the magnitudes of these effects are also allowed to differ. This method generates four economic disparity indicators, two each for poverty and education: $B L A C K$ poverty advantage (i.e. fewer blacks in poverty); BLACK 
education advantage; LATINO poverty advantage; LATINO education advantage. Equal status is the excluded category.

\section{The Material Roots of Prejudice}

How do material conditions shape black attitudes toward Latinos? My initial focus is on antagonism as expressed in "simple prejudice," defined as feelings of dislike and aversion toward a particular social group (Allport 1954). One dimension of prejudice is the tendency to view members of a group in collective rather than individual terms and to ascribe to those group members certain negative characteristics. Using a summary scale constructed from responses to a series of bi-polar trait rating items, I measure the degree to which blacks harbor strongly positive (low values) or strongly negative (high values) stereotypes about Latinos as a group. ${ }^{7}$

To estimate the effects of material conditions on anti-Latino prejudice, I regressed the summary stereotype score on a set of predictors that included the measures of block-group education and poverty, the four economic disparity indicators, and other relevant contextual and individual demographic variables. ${ }^{8}$ Because of the relationship between the racial and socioeconomic characteristics of neighborhoods, and the potential effect of each on racial attitudes, the model controls for both the proportion black and the proportion Latino in the block-group. Additionally, since inter-group economic disparity can exist only in neighborhoods where there are both black and Latino residents, each of the disparity indicators is interacted with the proportion Latino in the block-group. ${ }^{9}$ Finally, the model controls for individual-level demographic characteristics, including gender, age, socio-economic status, and length of residence in LA. These factors may be correlated both with levels of out-group hostility as well as with residential location. 
Table 1 presents coefficients and robust standard errors from a linear regression model predicting an individual's level of prejudice. ${ }^{10}$ The level of hostility directed at Latinos differs significantly based on the relative economic status of the black and Latino populations, even when other respondent and community characteristics are taken into account. The coefficients on Latino educational and poverty advantage, each interacted with proportion Latino, are both positive and statistically significant. African Americans who reside in integrated neighborhoods where Latinos are materially better-off than blacks harbor more negative stereotypes about the group.

\section{[TABLE 1 ABOUT HERE]}

The magnitude of these relationships, which are conditional on the size of the Latino population in the block group, can be seen more clearly in Figure 2, which plots the variation in the predicted stereotype score across levels of Latino economic advantage for two hypothetical racial environments: neighborhoods where Latinos constitute (1) 14 percent of the population (the $25^{\text {th }}$ percentile for blacks in the LA metropolitan area); and, (2) 51 percent (the $90^{\text {th }}$ percentile). All other independent variables are held constant at their mean or modal values. Where Latinos constitute only 14 percent of the population, increases in either the group's poverty or educational advantage are associated with small increases in negative attitudes among blacks. For example, when the percent of Latinos with a high school degree exceeds the percent of high school-educated blacks by 12 percentage points, the average among block groups where Latinos are advantaged relative to blacks, the predicted stereotype score is .20 points (or onequarter of a standard deviation) higher than it would be if blacks and Latinos shared similar status. But when Latinos constitute 51 percent of the population, the same 12-point educational advantage increases prejudice by .73 points, nearly one standard deviation. As evidenced by the 
graph's shallow slopes, disparities in the rates of poverty among the two groups have substantively smaller, although statistically significant, effects on black antagonism.

[FIGURE 2 ABOUT HERE]

But while situations of black disadvantage can activate hostility on the part of African Americans, the converse is not true. As Table 1 makes clear, in integrated environments where the material conditions of black life, as measured by educational attainment and rates of poverty, are superior to the conditions faced by Latinos there is no softening of racial attitudes, relative to the attitudes expressed in the context of status similarity. The coefficients on black educational and poverty advantage are both statistically insignificant. As long as African Americans are at least as well off as their Latino neighbors, the relative status of the two groups has no effect on blacks' racial attitudes.

The contextual effects associated with the material conditions of group life exceed those associated with the overall material condition of neighborhoods. Living in economically distressed neighborhoods does not itself provoke negative attitudes among blacks. Neither the overall rate of poverty or educational attainment has a statistically significant effect on expressions of prejudice. The stress of living in a resource-poor community is not the source of intolerant sentiments among African Americans.

Consistent with earlier findings by Oliver and Wong (2003), the model estimates a positive relationship between the size of the black population in the area and the level of racial prejudice. However, the coefficient estimated here is statistically significant only at the $10 \%$ level (two-tailed). More importantly, while Oliver and Wong (2003) inferred from their result that a large out-group population is associated with less out-group hostility, the statistically insignificant coefficient on Latino population size, together with the coefficients on the 
interactions between Latino population size and economic disparities, suggests a more complex relationship. In environments where blacks are at least as well-off as their Latino neighbors, the size of the Latino population in the area has no effect on sentiments toward the group. It is only in conditions of Latino economic advantage that the size of the Latino population is related to blacks' racial attitudes—and in those contexts the estimated effects are substantively small.

Figure 2 illustrates both the small size and conditional nature of the relationship between out-group size and out-group hostility. It is only when black poverty rates exceed Latino poverty rates by more than 18 percentage points (i.e. $.55 \div 3.0$, or the intersection of the line graphs), or when Latino educational attainment exceeds black educational attainment by more than five percentage points, that we observe a positive relationship between the size of the Latino population and levels of racial prejudice. ${ }^{11}$ Moreover, even at the most extreme disparity in educational attainment, a percentage point increase in the size of the Latino population increases the stereotype score by less than .05 points. The size of the proximate Latino population has a limited effect on the level of anti-Latino sentiment among blacks.

Thus, it is the material conditions of group life, more so than the size of groups or the material conditions in neighborhoods, that are instrumental in activating negative black attitudes. When Latinos command more economic resources than blacks we observe greater support for racist stereotypes. The size of the Latino population affects black attitudes primarily by amplifying African Americans' sensitivity to the economic disparities between the groups.

\section{The Material Roots of Political Conflict}

The preceding analysis established that inter-group economic disparities have an effect on one of the clearest expressions of antagonism toward an out-group, support for racist stereotypes. But if the economic disparities between groups can provoke feelings of dislike and 
aversion, are such disparities also implicated in actual political conflicts? In particular, do conditions of black disadvantage lead African Americans to engage in defensive political behavior, adopting positions at odds with the interests of Latinos as a group and, by extension, ill-suited to coalition building?

To explore the effects of economic disparity further, I examined its relationship to black support for affirmative action policies that benefit Latinos, an issue that has emerged as one axis of political conflict between the groups (Vaca 2004), and its effect on African Americans' willingness to view black and Latino interests as consonant, a necessary condition for sustainable coalitions. Two dynamics are of particular interest. First is the extent to which African Americans, who express strong support for affirmative action policies when targeted at blacks, are as willing to endorse these programs when specifically targeted at Latinos. Do blacks view Latinos as equally deserving of civil rights protections, or do they share the attitude of John Steward, a black school official in Los Angeles whose response to Latino calls for affirmative action was that such policies were "reparations" to Black Americans for their years of slavery and not for successfully crossing the "border 10 to 15 times a year" (quoted in Vaca 2004, 132)? The second dynamic of interest is whether African Americans consider (further) Latino advancement as necessarily detrimental to the economic and political well-being of blacks as a group, and as such not desirable. Or do African Americans recognize the two groups' "common stake in [the] struggles to transform U.S. society" (Vaca 2004, 150), making further improvements in the economic and political status of Latinos a goal they need not oppose?

I assess racial policy preferences with a set of questions regarding respondents' attitudes toward programs that extend "special job training and educational assistance" and those that guarantee "special preferences in hiring and promotion." On a series of five-point scales, 
ranging from "strongly oppose" to "strongly favor," respondents were surveyed on their levels of support for programs benefiting blacks and, separately, for efforts targeted at Latinos. I calculate the gap in support for each affirmative action policy by subtracting the Latino-beneficiary support score from the black-beneficiary score; the difference captures the degree of in-group policy favoritism on the part of blacks. I assess whether blacks perceive a tension between black and Latino group interests based on their responses - agree, disagree, neither- to two statements: that "more good jobs for Latinos means fewer good jobs for Blacks"; and, the "more influence Latinos have in local politics, the less influence Blacks have." (A random sub-sample of only half of the respondents [546] was asked about the consonance of black and Latino interests.) To test whether the degree of in-group favoritism and apprehensiveness about further Latino advancement, which together are taken as indicators of defensive political behavior, widen under conditions of economic disparity, I regressed the two comparative affirmative action measures and the two group interest measures on the same set of predictors used in Table 1. I add to the models controls for political ideology and partisanship, and for the group interest items I use an ordered probit specification. The results are presented in Table 2.

\section{[TABLE 2 ABOUT HERE]}

In contexts of black economic disadvantage, African Americans are not only more likely to harbor negative stereotypes about Latinos, they also are more reluctant to support the use of preferences in the hiring of Latinos to the same degree that they support such preferences for blacks and are more likely to view Latino economic advancement as at odds with their own group's interests. In the models predicting the level of in-group favoritism on affirmative action in hiring and promotion and apprehensiveness about Latino job gains, the coefficients on Latino educational and poverty advantage are positive and statistically significant at the five-percent 
level. (Educational advantage is statistically significant in the affirmative action model only.) Moreover, in the model predicting whether blacks consider Latino political advancement to be incompatible with black interests, the coefficient on Latino poverty advantage is also positive, though fall just short of conventional levels of statistical significance.

Similar to the patterns observed earlier, the sensitivity to economic disparity is conditional on the size of the Latino population, as illustrated more clearly in Figure 3. Where Latinos constitute only 14 percent of the neighborhood population, increases in the group's educational or poverty advantage are associated with only small increases in the degree of ingroup favoritism and in the likelihood of viewing black and Latino economic interests as incompatible. At 51 percent of the population, however, an increase in the Latino educational advantage widens the gap between support for black preferences and support for Latino preferences by a more considerable amount; for every one standard deviation increase in the educational advantage, in-group favoritism on preferential hiring increases by a standard deviation. And as the Latino poverty advantage in this context expands, the probability that a respondent will believe that Latino job gains come at the expense of blacks also increases considerably, from 58 percent when the groups are at parity to over 70 percent when black poverty exceeds Latino poverty by 20 points or more. (Predictions from the ordered probit model assume that all other factors are held constant at their mean or modal values.)

\section{[FIGURE 3 ABOUT HERE]}

In contrast to its effects on the gap in support for preferential hiring and on apprehensiveness about Latino economic (and, to a lesser extent, political) advancement, the relative status of blacks and Latinos has no statistically significant effect on whether African Americans support the extension of educational assistance to Latinos as strongly as they support 
similar efforts targeted at blacks. As indicated by the coefficients and standard errors on three of the four economic disparity interaction terms, neither conditions of black economic advantage or disadvantage influence the degree of in-group favoritism on educational assistance. The one exception is the measure of black educational advantage, which, like the coefficient on Latino poverty advantage in the model predicting concern over Latino political gains, falls just short of conventional levels of statistical significance $(\mathrm{p}<.06)$. The model estimates a negative relationship between black educational advantage and in-group favoritism. However, even if we allow for a less stringent test of statistical significance, the magnitude of the estimated effect is substantively insignificant; in a 51 percent-Latino context, favoritism increases by less than .01 for every percentage point advantage.

The material condition of neighborhoods is the one aspect of the economic environment with a statistically significant effect on the willingness to endorse educational assistance equally for both black and Latino beneficiaries. In high poverty contexts, African Americans favor their own group by a wider margin. The small coefficient on the poverty measure demonstrates, however, that even these effects are modest. With every 13 percentage point (one standard deviation) increase in the neighborhood's poverty rate, the level of in-group favoritism increases by only .09 points (one-seventh of a standard deviation). Unexpectedly, the model estimates a positive relationship between neighborhood educational composition and in-group favoritism. All else equal, African Americans in highly educated contexts are more supportive of educational assistance directed at blacks than similar efforts targeted at Latinos. ${ }^{12}$ The estimated effect size exceeds that of poverty, but again remains small when compared to the effects of status disparity on favoritism in hiring and apprehensiveness about Latino job gains; every standard deviation change in the proportion high school-educated is associated with one-fifth of 
a standard deviation change in the level of in-group favoritism in educational assistance. On balance, the economic context appears to be less a factor in the conflict over affirmative action policies, such as job-training and educational assistance, that increase the human capital attributes of a target group than it is in the conflict over preferential treatment and in the tendency to view black and Latino economic (if not political) interests as incompatible. And where economic context matters, it is the status disparity between groups that is most consequential.

\section{Anti-Latino Sentiment and the Determinants of Residential Choice}

An issue confronting cross-level research is the possibility that individual self-selection may account for the correlation between individual attitudes and contextual conditions. Racial predispositions, including attitudes toward out-groups, rather than being affected by residential context, as argued here, in fact may drive residential choice (Bobo and Zubrinsky 1996). Even African Americans, whose residential mobility is demonstrably more constrained than whites', may base their location decisions on their feelings toward Latinos, seeking out neighborhoods whose demographic characteristics reflect their own racial sensibilities. As a result, any crosslevel correlations may capture only "the geographic distribution of racial attitudes rather than any causal factor from the environment” (Oliver and Wong 2003, 577).

To assess the extent to which selection effects are responsible for the observed relationship between disparity and antagonism, I performed two diagnostic tests and scrutinized the theoretical logic underlying the self-selection hypothesis. First, following Branton and Jones (2005) and Oliver and Wong (2003), I modeled the block-group residence of each respondent to identify the individual-level attributes that predict residential location. ${ }^{13}$ I modeled block-group residence as a function of individual socio-economic status, length of residence in Los Angeles 
County, political ideology, and racial predispositions—specifically, preferences regarding the ideal racial composition of one's neighborhood and beliefs about the amount of discrimination faced by Latinos. ${ }^{14}$ Of particular interest is how strongly racial attitudes predict residential location. The regression analysis finds that, while individual-level attributes-including age, employment status, homeownership, and family income — are statistically significant predictors of block-group residence, there is no evidence of selection based on racial predispositions. Whether a respondent prefers to live primarily among other blacks or expresses a desire to live in a more integrated setting does not determine the type of block-group in which she resides—or, more precisely, these preferences are not effective in sorting individuals into neighborhoods that vary along the particular contextual dimension of interest here, inter-group disparity. (In-group preference may guide other dimensions of residential choice.) Similarly, whether or not a respondent believes that Latinos confront barriers to socio-economic attainment, as members of their own group do, is unrelated to residential location. In short, there is no evidence that the respondents most averse to the idea of living among out-group members and most skeptical about claims of anti-Latino discrimination tend to reside in "Latino-advantaged" block groups, the environments shown earlier to be associated with heightened levels of anti-Latino sentiment.

As a second test of selection effects, I reestimated the original models, conditioning the relationship between disparity and anti-Latino sentiment on the respondent's length of residence in LA County. If inter-group economic disparity hardens out-group attitudes, then we would expect to observe more pronounced effects among long-time LA residents who not only are more likely to have experienced the county's demographic changes (i.e. the movement of Latinos into black neighborhoods, the emergence of inter-group disparities) but also have been exposed to the contextual condition for a longer period of time. ${ }^{15}$ While the results of this diagnostic test make 
clear that there is not a monotonic, linear relationship between length of LA residence and the average size or statistical significance of the coefficients for Latino economic advantage, the results also indicate that the impact of Latino advantage on hostility is more likely to be positive and statistically significant among longer term residents of the county. In the models predicting stereotypes, in-group favoritism, and beliefs about the (in)compatibility of black and Latino economic interests, the average effect sizes for the Latino advantage measures are statistically greater than zero only among respondents who have resided in the county for more than 17 years (the $25^{\text {th }}$ percentile). Among newer residents, who are more likely to have settled in the area after the demographic transition, there is no statistically significant relationship between negative black attitudes and Latino advantage.

The final challenge to the self-selection hypothesis is that it is in conflict with the observed empirical relationships. If predisposition toward out-groups drives residential choice then, presumably, the expectation is that African Americans who harbor negative attitudes about Latinos will prefer neighborhoods in which blacks and not Latinos are the economically dominant group. In other words, we would expect that black economic advantage would be positively correlated with anti-Latino sentiment, while Latino economic advantage would be negatively correlated with expressions of hostility. Yet the results in Tables 1 and 2 show just the opposite. To the extent that self-selection confounds the observed relationships, it is more likely that the models underestimate rather than overestimate the effect of Latino advantage on antiLatino sentiment. In sum, on both theoretical and empirical grounds, there is little reason to suspect that self-selection is responsible for the cross-level correlation between disparity and antagonism.

\section{Conclusion}


The growing ethnic diversity of the United States has transformed the residential experiences of many black Americans. Early reports indicate that the transition to a "prismatic metropolis" has not been smooth (Bobo and Johnson 2000). Despite periodic elite efforts to cooperate across racial and ethnic lines, distrust and, at times, open conflict have characterized the response of the black mass public to Latino ascendancy. Most accounts of black-Latino relations locate the source of negative black attitudes in the inter-group competition for scarce resources, attributing antagonism among blacks to fears of material deprivation. In this article, I considered how the environment in which blacks live can amplify the material anxieties at the base of anti-Latino sentiment. While previous scholars have centered their analyses on racial environments, the results here suggest that it is less the relative size of racial groups and more the economic resources these groups command that influences black attitudes. Where Latinos enjoy an economic advantage relative to blacks, African Americans are more likely to express racial prejudice toward the group and to engage in defensive political behavior.

What emerges from the analysis of prejudice and political conflict is an image of two groups locked in competitive social relations, where tangible signs of greater out-group advancement are sufficient to amplify fears and activate hostility. Yet just as it is true that Latinos and blacks often compete for jobs, educational resources, and political power, it is also true that the two groups share similar objective circumstances relative to whites. Competition and commonality may work at cross-purposes in shaping black attitudes toward Latinos: competition may predispose blacks toward negative attitudes; recognition of a shared disadvantage relative to whites might encourage a more positive orientation. Perhaps social environments influence black attitudes by privileging one fact of black-Latino relations over the other. In particular, economic disparities in the immediate environment may heighten the 
salience of competition, while distracting attention from the larger dynamic of subordination to whites. Even in the face of economic disparities, blacks may recognize similarities in the overall condition of Blacks and Latino. But the fact that Latinos also suffer discrimination and limited life chances may recede in importance as an influence on racial attitudes. Instead, the competition between groups — and the anxieties and fears that surround that competition — may become the more important determinant of attitudes, increasing the odds of hostility.

The role of economic disparity in activating anti-Latino sentiment highlights one challenge presented by an increasingly multiethnic society. The growing diversity of cities and neighborhoods may not be the greatest threat to inter-group comity, although journalists often frame black-Latino relations in those terms. In contrast to the behavior of white Americans, whose hostility toward minority out-groups rises in direct proportion to the size of the proximate minority population, for African Americans size and proximity alone are not always enough to provoke hostility. But while black antagonism may not be the inevitable by-product of ethnic diversity, it may still defy easy resolution. To ensure diversity without antagonism, a fundamental challenge will be to resolve the economic insecurities that discourage blacks from making common cause with Latinos. The greatest threat to inter-group comity may not be that blacks and Latinos increasingly live side-by-side, but that they do so at a time of declining economic fortunes for large segments of the black population.

As I noted earlier, using the 1992-1993 LASUI requires caution when interpreting the empirical results. The strength of the database is the large sample of black respondents who reside in (black-Latino) integrated neighborhoods, making it possible to test a variety of contextual hypotheses. The weakness is that the data are drawn from a single metropolitan area-an area that was among the first to experience the demographic changes, now unfolding 
throughout the country, responsible for the growing residential integration of blacks and Latinos-and as such may not be representative of the nation's black population. Moreover, the data are more than a decade old, collected at a time in Los Angeles when the Latino population, although large, had yet to convert its demographic clout into real political power-and long before Latinos, nationally, would replace African Americans as the country's largest minority group, courted assiduously by both political parties. ${ }^{16}$ The nature of the data sample may limit the generalizability of the results.

Yet I believe the analysis presented here makes a compelling case for scholars to pay at least as much attention to the relative economic status of minority groups as they typically do to the groups' relative sizes in their research on inter-group relations in general and black racial attitudes in particular. Additionally, there is no reason to believe that a decade of demographic and political changes, in Los Angeles and nationally, have undercut the contemporary relevance of the basic dynamic uncovered here- - hostility in the face of disadvantage. If anything, the fact that status differences in integrated settings could provoke hostility even when the locally advantaged group, though large in number, did not hold a privileged position in the wider metropolitan, state, or national context suggests that the expansion and consolidation of Latino power - as demonstrated, for example, by the 2005 election of a Latino mayor in Los Angelesmay only heighten the salience of inter-group disparities. As black-Latino residential integration spreads beyond cities like Los Angeles and Houston to Memphis, TN and Durham, NC, the findings from LA alert us to the possibility that economic disparities between blacks and Latinos may play an important role in how African Americans respond to their new neighbors. And as Latinos in Los Angeles in particular enjoy more of the political benefits that come with their demographic clout, we may find that the hostilities provoked by status disparity may no longer 
be limited to just those neighborhoods with large Latino populations; even African Americans in minimally-integrated settings may react negatively to any signs of difference. With the benefit of more contemporary and national data, as well as a survey instrument concerned with both the individual attributes of respondents as well as the collective attributes of their neighborhoods, future research may reveal more fully and conclusively the contextual roots of anti-Latino sentiment among blacks.

Whether the black mass public harbors negative stereotypes about Latinos, are equally willing to address the discriminatory barriers faced by both groups, and believe that black and Latino economic and political interests are compatible has important implications for coalition politics. Much of the academic literature on minority politics has emphasized the objective shared interests of non-white groups and, especially, the commitment of political elites as the positive bases for alliance (e.g. Browning, Marshall, and Tabb 1984). As Kaufmann (2003a, 2003b) observes, this view discounts the perceptions of shared values and shared interests that in fact are requisite for durable coalitions at the mass level. Such coalitions cannot be sustained by elite efforts alone. Not only are individuals not bound by elite arrangements, they are not always attentive to elite cues (Kaufmann 2003b).

Cooperation at the mass level ultimately turns on the beliefs and attitudes that guide mass behavior (Tedin and Murray 1994). A group stereotyped as "difficult to get along with" or as "people to fear" is unlikely to be viewed as a potential partner; and, by the same token, a group whose members voice such intolerant sentiments may find it difficult to attract or retain a diverse base of support. Moreover, a group reluctant to extend to another the same policy benefits they themselves enjoy — and, in fact, views any advancement by the other group as harmful to their own interests - also may face dim coalition prospects. In short, prejudice, in-group policy 
favoritism, and opposition to out-group advancement exemplify the kinds of attitudes that impede cooperation across racial and ethnic lines (Kamasaki and Yzaguirre 1994). History has shown that such cooperation is critical for the full force of the minority vote to be felt. As black political elites increasingly recognize, the need for coalitions only deepens as Latino population growth continues to outpace black population growth. Conditions that heighten negative attitudes have potentially far-reaching implications, as they undermine the very strategy that is needed to address the continuing problem of inequality. 


\section{Endnotes}

${ }^{1}$ Research suggests that negative attitudes on the part of Latinos are also to blame for the lack of inter-group cooperation (e.g. Kaufmann 2003b; Tedin and Murray 1994).

${ }^{2}$ It has also been argued that residential integration with Latinos, by offering expanded opportunities for social contact between the two minority groups, may help counter fears of displacement and reduce hostility (Bobo and Johnson 2000; Oliver and Wong 2003).

${ }^{3}$ Data from similar surveys conducted in Atlanta, Boston, and Detroit could not be incorporated because the samples included too few black respondents from neighborhoods with Latino residents, making it impossible to address many of the questions of interest here.

${ }^{4}$ The neighborhood is not the only relevant contextual unit when considering the environmental determinants of black-Latino relations. However, for the each of the hypotheses tested here, the neighborhood is a relevant contextual unit. The economic resources available at this level materially affect socio-economic well-being as well as quality of life, and as such may contribute to the feelings of vulnerability and stress at the base of out-group hostility (H1). Moreover, individuals are more likely to be aware of and materially affected by inter-group economic disparities when such disparities are present at the neighborhood-level, where they are readily perceived and are manifest in tangible ways (H2).

${ }^{5}$ Mean (SD): Proportion high school-educated: .68 (.16); Proportion below poverty: .18 (.13).

6 The raw data described by the histograms are at the block-group level and are not adjusted to reflect the fact that respondents were not sampled equally across block-groups. The text boxes embedded in each histogram indicate the (weighted) percent of blacks in LA who live in block groups with difference scores either above or below zero. 
7 Respondents evaluated Latinos on six dimensions: intelligence, self-sufficiency, sociability, involvement in drugs and gangs, tendency to be poor, and treatment of out-groups. Responses to these stereotype items, each measured on a 7-point scale, were combined in an unweighted average to construct the summary measure of prejudice. Mean (SD): $4.3(.74)$ 8 Ideally a hierarchical model would be used to analyze this multi-level dataset; I attempted to do so using HLM Version 5.04. However, because of the small size and the variability of the block group-level samples (1 to 34 respondents, with a median of 4 ) the data proved ill-suited to multi-level estimation. While it was possible to estimate fixed regression coefficients, I could not draw inferences about random coefficients or estimate the variance components at the cluster-level. Instead of a hierarchical model, I used the robust variance estimator (White 1982) to address the statistical challenges (i.e. correlated error terms) presented by the clustered data. ${ }^{9}$ Put another way, the variables measuring inter-group disparities are only observed for that subset of cases where the proportion Latino is greater than zero. In the multiplicative interaction models tested here, where the disparity measures are included only as part of interaction terms, the implicit assumption is that disparities have no effect on attitudes where the proportion Latino is zero. (Were this not true, the omission of direct disparity measures, the "constitutive terms" in the interaction models, would result in potentially severe inferential errors [Brambor et al. 2006].) To gauge the average (unconditional) effect of disparity on attitudes, I reestimated the models using only the subset of cases where the proportion Latino is greater than zero and including the disparity measures as direct effects rather than as part of interaction terms. The substantive results from these linear-additive models were consistent with the findings from the interactive-conditional models. As expected, however, the coefficients on the disparity measures, 
which in the linear-additive model are weighted averages of the conditional effects (and, therefore, are sensitive to the distribution of proportion Latino in the data), were attenuated. (Relatively few respondents reside in the heavily-Latino block groups where the effects of disparity are found to be greatest.) The weighted-average effects associated with Latino poverty advantage remained statistically significant; those associated with Latino educational advantage were statistically insignificant in the linear-additive models.

${ }^{10}$ Prior to performing the statistical analyses presented here, I addressed the problem of incomplete data due to item nonresponse. Rather than rely on listwise deletion to cope with the problem of missing data, I opted for multiple imputation, using King et al.'s (2001) EMis algorithm. Statisticians have demonstrated that multiple imputation, which uses information in the observed data to "predict" the likely values of the unobserved data, outperforms listwise deletion by correcting for the inefficiency and bias that results from the latter approach (e.g. Schafer and Olsen 1998). I imputed a total of 30 complete datasets-five separate datasets for each of my five dependent variables, and five additional datasets for the tests of self-selection. Each complete dataset was analyzed. All of the results presented in the proceeding tables and graphs are the combined results across datasets (Rubin 1987).

${ }^{11}$ Evidence of a positive relationship is the fact that, at every advantage level above these intersection points, the stereotype score associated with 51 percent Latino (the dotted line) exceeds the score associated with 14 percent Latino (solid line).

${ }^{12}$ This result is at odds with the hypothesis that resource scarcity should be associated with defensive political behavior. Perhaps the experience of living in highly-educated contexts, rather than leading blacks to feel more generous toward out-groups, only strengthens their support for 
programs that might succeed in giving other blacks access to similar environments. The positive coefficient may not reflect waning support for Latino affirmative action so much as it reflects more resolute support for black affirmative action. Separate analyses provide some support for this interpretation; block group education is positively correlated with support for black educational assistance, but only weakly (though positively) correlated with support for Latino assistance.

${ }^{13}$ For each economic dimension (education or poverty), I constructed an unordered, categorical variable coded to reflect the type of block group in which the respondent lives: (1) Latinoadvantaged; (2) Black-advantaged; (3) Equal status; (4) Not Black-Latino integrated. The respondent's block-group residence was modeled using a multinomial logistic regression, with "not integrated" as the base category.

14 Preferred Composition: Respondents rank-ordered a series of cards depicting neighborhoods of varying racial composition. Each card displayed 15 homes, with "black" households identified by color. The preferred composition is measured by the proportion of "black" households in the respondent's top-ranked neighborhood: 0 (no blacks), 0.13 (two black households), .47 (seven), .66 (ten), 1 (all black). Discrimination Beliefs: Respondents were asked "In general, how much discrimination is there that hurts the chances of [Latinos] to get good paying jobs? A lot, some, only a little, or none?"

${ }^{15}$ Respondents were sorted based on their length of residence in LA: (1) 17 years or less $\left(25^{\text {th }}\right.$ percentile); (2) $17-27$ years ( $25^{\text {th }}$ to $50^{\text {th }}$ percentile); (3) $27-36$ years ( $50^{\text {th }}$ to $75^{\text {th }}$ percentile); (4) over 36 years. For each quartile, I modeled prejudice, in-group policy favoritism, and beliefs 
about the compatibility of black and Latino interests as functions of the same set of predictors listed in Tables 1 and 2.

${ }^{16}$ For example, the relative unimportance of Latino population size as a direct predictor of political attitudes may be an artifact of the particular setting in which these data were collected, early 1990s Los Angeles. Given a larger metropolitan context in which Latinos had yet to emerge as significant political actors, perhaps size and proximity alone were not enough to provoke anxiety. In 2005, after the election of the city's first Latino mayor and a decade in which the number of Latino state legislators nearly doubled, the prospect of Latino consolidation of political power may seem more real. In such a context, group size itself may take on new salience. I credit an anonymous reviewer for this important insight. 


\section{References}

Alba, Richard, and John Logan. 1991. "Variations on Two Themes: Racial and Ethnic Patterns in the Attainment of Suburban Residence.” Demography. 28 (August): 431453.

Alba, Richard, John Logan, and Paul Bellair. 1994. "Living with Crime: The Implications of Racial/Ethnic Differences in Suburban Location." Social Forces. 73 (December): $395-434$.

Allport, Gordon. 1954. The Nature of Prejudice. Cambridge, MA: Addison-Wesley Publishing Company.

Alozie, Nicholas O., and Enrique J. Ramirez. 1999. “"A Piece of the Pie’ And More: Competition and Hispanic Employment on Urban Police Forces." Urban Affairs Review. 34(3): 456-75.

Blalock, Hubert M. 1967. Toward a Theory of Minority-Group Relations. New York: Wiley.

Bobo, Lawrence, and Vincent Hutchings. 1996. "Perceptions of Racial Group Competition: Extending Blumer's Theory of Group Position to a Multiracial Social Context." American Sociological Review. 61(December): 951-72.

Bobo, Lawrence D. and Devon Johnson. 2000. "Racial Attitudes in a Prismatic Metropolis: Mapping Identity, Stereotypes, Competition, and Views on Affirmative Action." In Prismatic Metropolis: Analyzing Inequality in Los Angeles, ed. Lawrence Bobo, Melvin Oliver, James Johnson, and A. Valenzuela. New York: Russell Sage Foundation. 
Bobo, Lawrence D., and Michael P. Massagli. 2001. "Stereotyping and Urban Inequality." In Urban Inequality, ed. Alice O'Connor, Chris Tilly, and Lawrence D. Bobo. New York: Russell Sage Foundation, 89-162.

Bobo, Lawrence, and Camille Zubrinsky. 1996. "Attitudes on Residential Integration: Perceived Status Differences, Mere In-Group Preference, or Racial Prejudice?” Social Forces. 74(3):883-909.

Bobo, Lawrence, C.L. Zubrinsky, James Johnson, and Melvin L. Oliver. 1994. "Public Opinion Before and After A Spring of Discontent.” In The Los Angeles Riots: Lessons from the Urban Future, ed. Mark Baldassare. Boulder: Westview Press.

Brambor, Thomas, William Roberts Clark, and Matt Golder. 2006. "Understanding Interaction Models: Improving Empirical Analyses.” Political Analysis. 14 (1): 63-82.

Branton, Regina P., and Bradford S. Jones. 2005. "Re-Examining Racial Attitudes: The Conditional Relationship Between Diversity and Socio-Economic Environment.” American Journal of Political Science. 49(2):359-372.

Browning, Rufus, Dale Rogers Marshall, and David Tabb. 1984. Protest is Not Enough: The Struggle of Blacks and Hispanics for Equality in Urban Politics. Berkeley: University of California Press.

Cain, Bruce, Jack Citrin, and Cara Wong. 2000. Ethnic Context, Race Relations, and California Politics. . San Francisco: Public Policy Institute of California.

Camarillo, Albert M. 2004. "Black and Brown in Compton: Demographic Change, Suburban Decline, and Intergroup Relations in a South Central Los Angeles Community, 1950 to 2000.” In Not Just Black and White, ed. Nancy Foner and George Fredrickson. New York: Russell Sage Foundation. 
Cummings, Scott, and Thomas Lambert. 1997. "Anti-Hispanic and Anti-Asian Sentiments among African Americans.” Social Science Quarterly. 78(2):338-53.

Falcon, Angelo. 1988. "Black and Latino Politics in New York City: Race and Ethnicity in a Changing Urban Context." In Latinos and the Political System, ed. F. Chris Garcia. Notre Dame, IN: University of Notre Dame Press.

Frey, William H., and R. Farley. 1996. "Latino, Asian, and Black Segregation in U.S. Metropolitan Areas: Are Multi-ethnic Metros Different.” Demography. 33 (1): 35-50.

Gay, Claudine. 2004. "Putting Race in Context: Identifying the Environmental Determinants of Black Racial Attitudes.” American Political Science Review. 98(4):547-562.

Giles, Michael W., and Arthur S. Evans. 1986. "The Power Approach to Intergroup Hostility." Journal of Conflict Resolution. 30(3):469-86.

Glaeser, Edward L., and Jacob L. Vigdor. 2001. Racial Segregation in the 2000 Census: Promising News. Washington, D.C.: Brookings Institution, Center on Urban and Metropolitan Policy.

Glaser, James. 1994. "Back to the Black Belt: Racial Environment and White Racial Hostility in the South.” Journal of Politics. 56(1):21-41.

Guzman, Betsy. 2001. Census 2000 Brief: The Hispanic Population. Washington, D.C.: Department of Commerce.

Hero, Rodney E. 1989. "Multiracial Coalitions in City Elections Involving Minority Candidates: Some Evidence from Denver." Urban Affairs Quarterly. 25 (2): 342-51. Horowitz, Donald. 1985. Ethnic Violence. Cambridge, MA: Harvard University Press. 
Johnson, James, and Melvin Oliver. 1989. "Interethnic Minority Conflict in Urban America: The Effects of Economic and Social Dislocations." Urban Geography. 10(5): 449-463.

Kamasaki, Charles, and Raul Yzaguirre. 1994. "Black-Hispanic Tensions: One Perspective.” Journal of Intergroup Relations. 21(4):17-40.

Kaufmann, Karen. 2003a. "Minority Empowerment in Denver, Co.: How Black and Latino Voters Respond to Each Other's Political Leadership." Political Science Quarterly. 118 (1): 107-125.

Kaufmann, Karen. 2003b. “Cracks in the Rainbow: Group Commonality as a Basis for Latino and African-American Political Coalitions." Political Research Quarterly. 56(2): 199-210.

King, Gary, James Honaker, Anne Joseph, and Kenneth Scheve. 2001. “Analyzing Incomplete Political Science Data: An Alternative Algorithm for Multiple Imputation." American Political Science Review. 95(1):49-69.

Kluegel, James R., and Eliot R. Smith. 1986. Beliefs About Inequality: Americans' Views of What Is and What Ought To Be. New York: Aldine de Gruyter.

Logan, John. 2001. Ethnic Diversity Grows, Neighborhood Integration Lags Behind. Albany, NY: Lewis Mumford Center, State University of New York. Massey, Douglas S., and Nancy A. Denton. 1993. American Apartheid. Cambride, MA: Harvard University Press.

McClain, Paula D. 1993. "The Changing Dynamics of Urban Politics: Black and Hispanic Municipal Employment-Is There Competition?” Journal of Politics. 55(2): $399-414$. 
McClain, Paula D., and Albert Karnig. 1990. "Black and Hispanic Socio-Economic and Political Competition.” American Political Science Review. 84(June): 535-45.

McClain, Paula D. and Steven Tauber. 1998. "Black and Latino Socio-Economic and Political Competition: Has a Decade Made a Difference?” American Politics Quarterly. 26(2): 237-52.

McClain, Paula D. and Steven Tauber. 2001. "Racial Minority Group Relations in a Multiracial Society.” In Governing American Cities, ed. Michael Jones-Correa. New York: Russell Sage Foundation.

Meier, Kenneth J., and Joseph Stewart Jr. 1991. "Cooperation and Conflict in Multiracial School Districts." The Journal of Politics. 53 (4): 1123-33.

Mindiola, Tatcho Jr., Yolanda F. Niemann, and Nestor Rodriguez. 2002. Black-Brown Relations and Stereotypes. Austin,TX: University of Texas Press.

Mohl, Raymond A. 2003. "Globalization, Latinization, and the Nuevo New South." Journal of American Ethnic History. 22 (4): 31-66.

Oliver, J. Eric, and Tali Mendelberg. 2000. "Reconsidering the Environmental Determinants of White Racial Attitudes.” American Journal of Political Science. 44(3):574-89.

Oliver, J. Eric, and Janelle Wong. 2003. "Intergroup Prejudice in Multiethnic Settings." American Journal of Political Science. 47(4):567-582.

Phelan, Thomas. J. and Mark Schneider. 1996. "Race, Ethnicity, and Class in American Suburbs." Urban Affairs Review. 31 (May): 659-680.

Rubin, Donald B. 1987. Multiple Imputation for Nonresponse in Surveys. New York: J. Wiley and Sons. 
Schafer, Joseph L., and Maren K. Olsen. 1998. "Multiple Imputation for Multivariate Missing-Data Problems: A Data Analyst's Perspective.” Multivariate Behavioral Research. 33(4):545-71.

Sears, David, Jack Citrin, Sharmaine V. Cheleden, and Colette van Laar. 1999. "Cultural Diversity and Multicultural Politics: Is Ethnic Balkanization Psychologically Inevitable?" In Cultural Divides: Understanding and Overcoming Group Conflict, ed. Deborah Prentice and Dale Miller. New York: Russell Sage.

Taylor, Marylee. 2000. “The Significance of Racial Context.” In Racialized Politics, ed. David Sears, Jim Sidanius, and Lawrence Bobo. Chicago: University of Chicago. Tedin, Kent L., and Richard W. Murray. 1994. "Support for Biracial Political Coalitions Among Blacks and Hispanics.” Social Science Quarterly. 75(4):772-789.

White, Halbert. 1982. "Maximum Likelihood Estimation of Misspecified Models." Econometrica. 50 (January): 1-26.

Vaca, Nicolas. 2004. Presumed Alliance. New York: Harper Collins. 


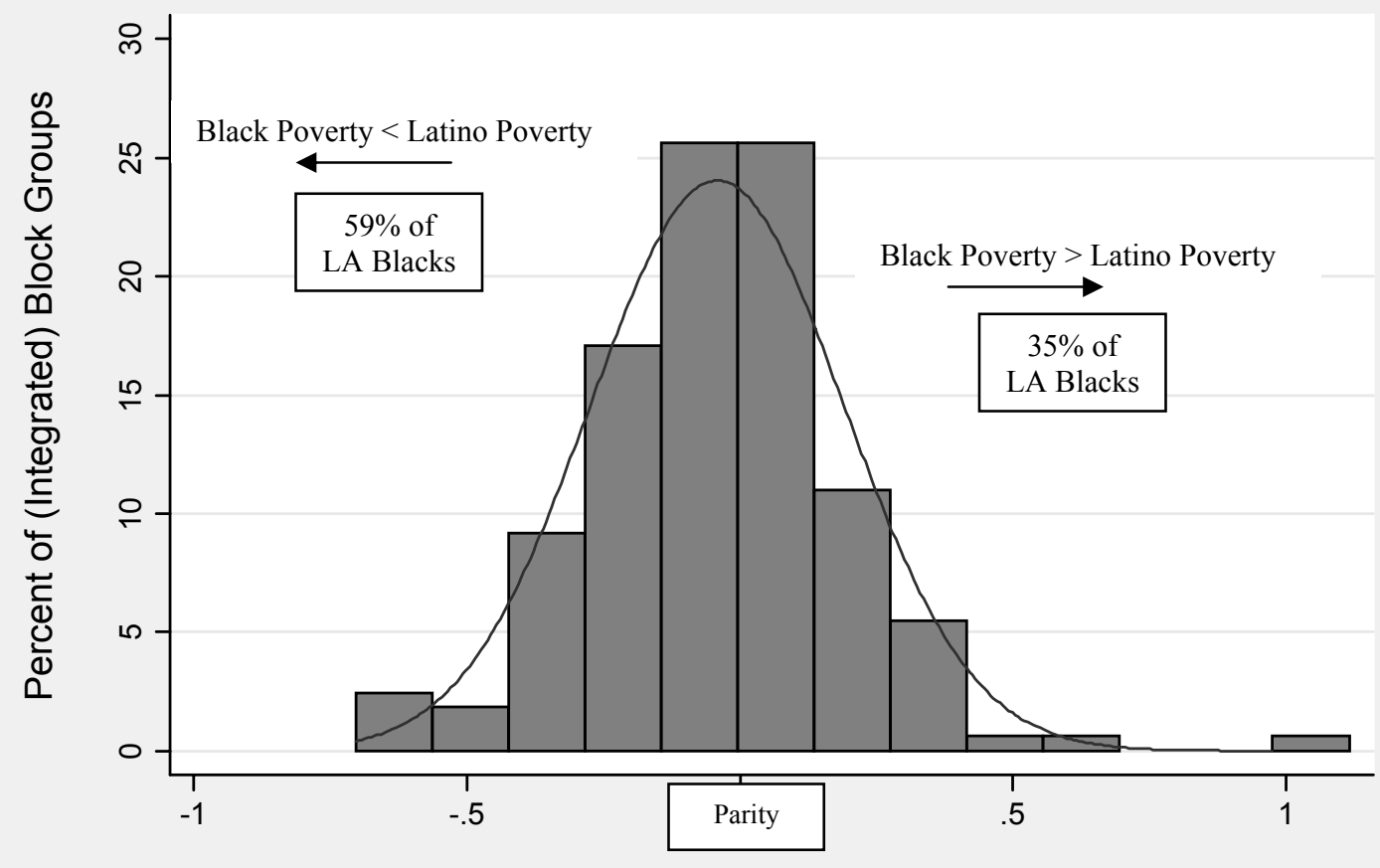

Poverty Disparity

(Black Poverty Rate - Latino Poverty Rate)

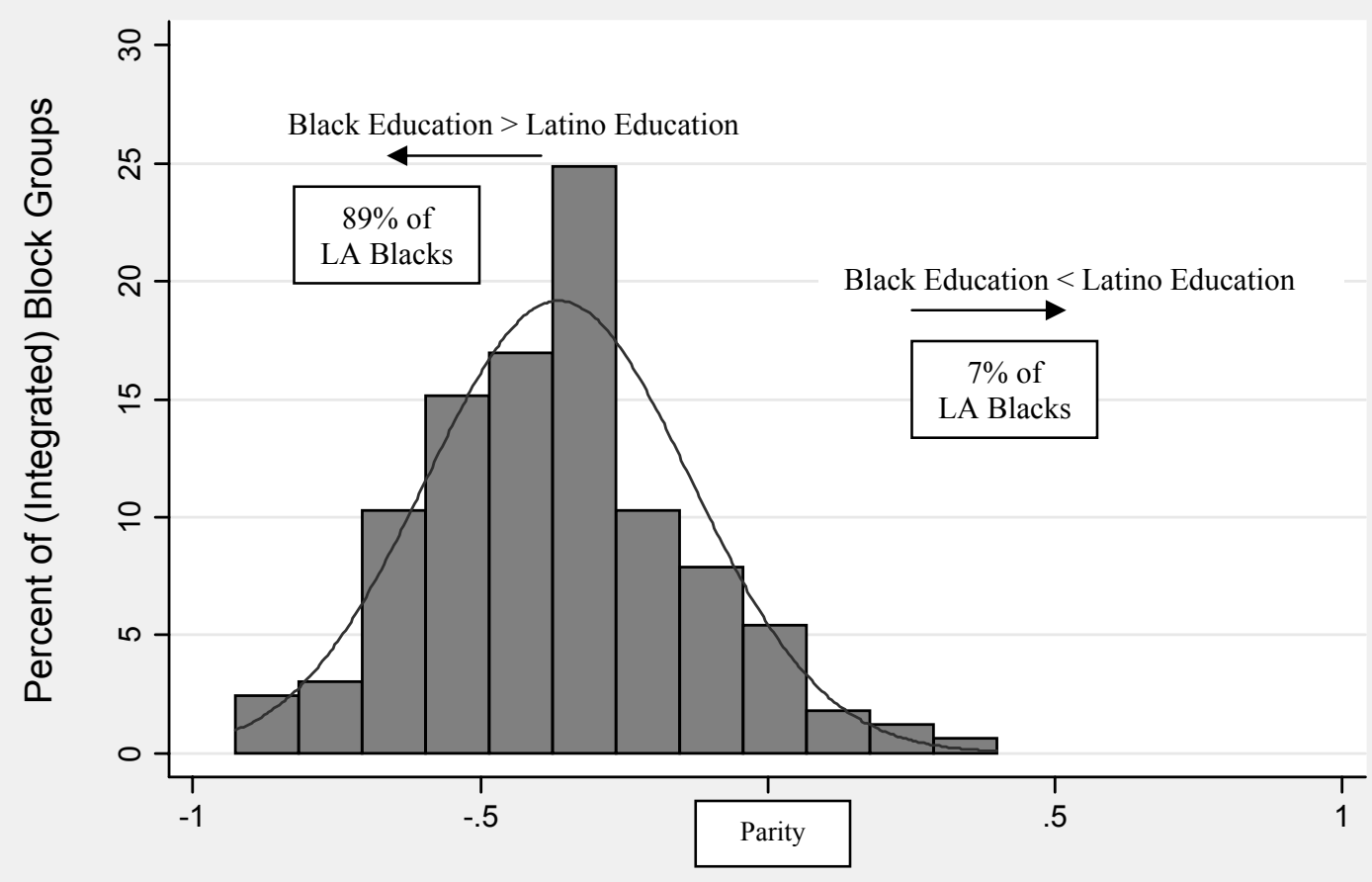

Education Disparity

(Latino Education Rate - Black Education Rate)

Note: Histograms describe unweighted distribution of difference scores at the block-group level, for the 165 integrated block-groups represented in the Los Angeles sample. Text boxes indicate the weighted percent of blacks residing in block groups above or below the parity threshold. 
TABLE 1: Predicting Negative Stereotypes

\begin{tabular}{|c|c|c|}
\hline Variables & & \\
\hline CONSTANT & 4.8 & $(.54)^{\star *}$ \\
\hline \multicolumn{3}{|l|}{ ECONOMIC CONTEXT } \\
\hline \multicolumn{3}{|l|}{ Neighborhood Material Conditions } \\
\hline Proportion Below Poverty & -.47 & $(.42)$ \\
\hline Proportion Highschool Educated & -.58 & $(.56)$ \\
\hline \multicolumn{3}{|l|}{ Group Material Conditions } \\
\hline Black Poverty Advantage * Prop. Latino & 1.3 & $(.92)$ \\
\hline Black Education Advantage * Prop. Latino & -.20 & $(.81)$ \\
\hline Latino Poverty Advantage * Prop. Latino & 3.0 & $(1.4)^{*}$ \\
\hline Latino Education Advantage * Prop. Latino & 11.9 & $(5.4)^{*}$ \\
\hline \multicolumn{3}{|l|}{ RACIAL CONTEXT } \\
\hline Proportion Black & .35 & $(.19)$ \\
\hline Proportion Latino & -.55 & (.58) \\
\hline \multicolumn{3}{|l|}{ INDIVIDUAL CONTROLS } \\
\hline Gender & -.03 & $(.08)$ \\
\hline Age & .00 & $(.00)$ \\
\hline Education & -.05 & $(.06)$ \\
\hline Family Income & -.00 & $(.00)$ \\
\hline Homeownership & .10 & (.11) \\
\hline Employed & .18 & $(.13)$ \\
\hline Unemployed & .33 & $(.17)^{*}$ \\
\hline Retired & .14 & $(.17)$ \\
\hline Length of Residence in LA & -.00 & $(.00)$ \\
\hline$R^{2}$ & \multicolumn{2}{|c|}{.11} \\
\hline$N$ & \multicolumn{2}{|c|}{1102} \\
\hline
\end{tabular}

Note: Coefficients and robust standard errors from linear regression model, with summary stereotype score as dependent variable. Higher values indicate more negative stereotypes. Parameter estimates and goodness of fit measures are combined statistical results across five multiply imputed datasets. ${ }^{*} p<.05,{ }^{* *} p<.01$. 
FIGURE 2: Predicted Stereotype Score
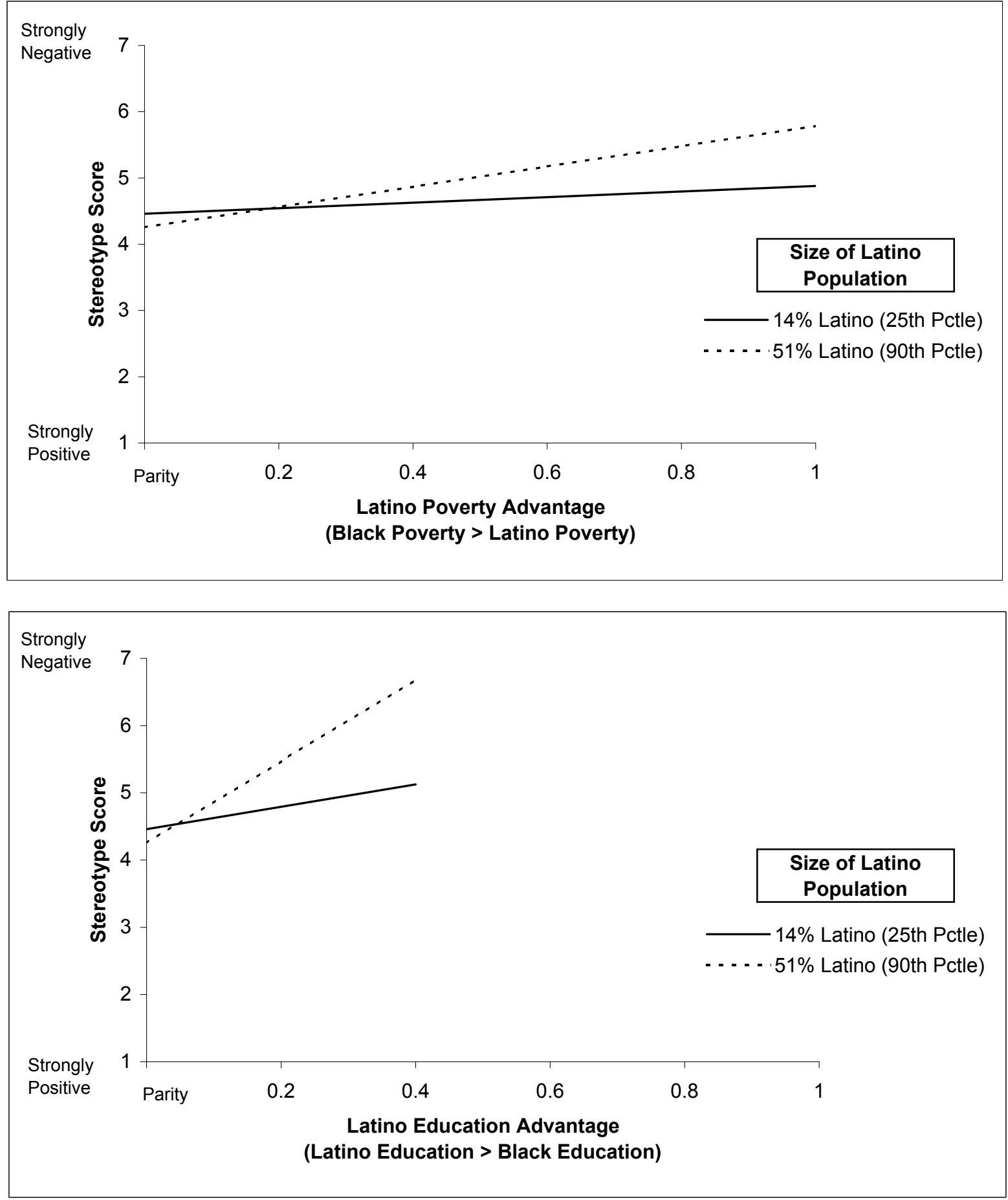

Note: Each graph depicts the predicted stereotype score across levels of Latino economic advantage for two levels of percent Latino, holding all other independent variables constant at their means. The predictions are derived from the linear regression estimates reported in Table 1. 
TABLE 2: Predicting Differential Affirmative Action Support and Beliefs About Group Interests

\begin{tabular}{|c|c|c|c|c|c|c|c|c|}
\hline \multirow[b]{3}{*}{ Variables } & \multicolumn{4}{|c|}{ Affirmative Action } & \multicolumn{4}{|c|}{ Compatibility of Group Interests } \\
\hline & \multicolumn{2}{|c|}{$\begin{array}{l}\text { Preferences in Hiring and } \\
\text { Promotion }\end{array}$} & \multicolumn{2}{|c|}{$\begin{array}{l}\text { Special Job-Training and } \\
\text { Educational Assistance }\end{array}$} & \multicolumn{2}{|c|}{$\begin{array}{l}\text { More Jobs for Latinos, Fewer } \\
\text { for Blacks }\end{array}$} & \multicolumn{2}{|c|}{$\begin{array}{l}\text { More Political Power for } \\
\text { Latinos, Less for Blacks }\end{array}$} \\
\hline & Coefficient & SE & Coefficient & SE & Coefficient & SE & Coefficient & SE \\
\hline CONSTANT & -.49 & $(.48)$ & -1.0 & $(.44)^{*}$ & & & & \\
\hline \multicolumn{9}{|l|}{ ECONOMIC CONTEXT } \\
\hline \multicolumn{9}{|l|}{ Neighborhood Material Conditions } \\
\hline Proportion Below Poverty & .24 & $(.33)$ & .71 & $(.29)^{\star *}$ & -.13 & $(1.0)$ & -.01 & $(.83)$ \\
\hline Proportion Highschool Educated & .62 & $(.39)$ & .98 & $(.37)^{\star \star}$ & -.57 & $(1.6)$ & -2.2 & $(1.4)$ \\
\hline \multicolumn{9}{|l|}{ Group Material Conditions } \\
\hline Black Poverty Advantage * Prop. Latino & .25 & $(.79)$ & -.55 & $(.64)$ & .20 & $(1.6)$ & 2.1 & $(2.4)$ \\
\hline Black Education Advantage * Prop. Latino & -.08 & $(.54)$ & -.57 & $(.30)$ & -.85 & $(1.3)$ & -1.3 & $(1.4)$ \\
\hline Latino Poverty Advantage * Prop. Latino & 1.5 & $(.58)^{\star *}$ & -.34 & $(.38)$ & 6.3 & $(2.4)^{\star \star}$ & 2.3 & $(1.2)$ \\
\hline Latino Education Advantage * Prop. Latino & 12.6 & $(6.3)^{*}$ & -2.3 & $(2.6)$ & 5.3 & $(16.3)$ & -12.8 & $(13.0)$ \\
\hline \multicolumn{9}{|l|}{ RACIAL CONTEXT } \\
\hline Proportion Black & .44 & $(.16)^{\star *}$ & .55 & $(.14)^{\star *}$ & .52 & $(.68)$ & -.57 & $(.65)$ \\
\hline Proportion Latino & .12 & $(.42)$ & .51 & $(.32)$ & .43 & $(1.8)$ & -2.0 & (1.5) \\
\hline \multicolumn{9}{|l|}{ INDIVIDUAL CONTROLS } \\
\hline Gender & .06 & $(.06)$ & .07 & $(.06)$ & .22 & $(.17)$ & .23 & $(.21)$ \\
\hline Age & .00 & $(.00)$ & .00 & $(.00)$ & .00 & $(.01)$ & -.02 & $(.01)^{*}$ \\
\hline Education & .02 & $(.03)$ & -.01 & $(.02)$ & -.13 & (.12) & -.15 & $(.10)$ \\
\hline Family Income & -.00 & $(.00)$ & -.00 & $(.00)$ & -.00 & $(.00)$ & -.00 & $(.00)$ \\
\hline Homeownership & -.03 & (.09) & -.18 & $(.07)^{*}$ & .10 & $(.28)$ & .27 & $(.25)$ \\
\hline Employed & -.12 & $(.10)$ & -.01 & $(.08)$ & -.10 & (.19) & -.10 & (.19) \\
\hline Unemployed & .24 & $(.12)^{*}$ & .16 & (.09) & .14 & $(.29)$ & .33 & $(.26)$ \\
\hline Retired & -.19 & $(.13)$ & .01 & $(.10)$ & .27 & $(.37)$ & .45 & $(.36)$ \\
\hline Length of Residence in LA & -.00 & $(.00)$ & .00 & $(.00)$ & .01 & $(.01)$ & .02 & $(.01)^{*}$ \\
\hline Liberal & .13 & $(.08)$ & .02 & $(.06)$ & .68 & $(.25)^{\star \star}$ & .38 & $(.19)^{*}$ \\
\hline Conservative & .07 & $(.08)$ & .11 & $(.07)$ & .81 & $(.27)^{\star \star}$ & .39 & $(.22)$ \\
\hline Democrat & -.11 & (.10) & .04 & (.08) & -.18 & $(.31)$ & .75 & $(.24)^{* *}$ \\
\hline Republican & -.24 & $(.13)$ & -.02 & (.11) & -.28 & (.65) & .99 & $(.57)$ \\
\hline Threshold 1 & & & & & -.10 & $(1.8)$ & -2.1 & (1.6) \\
\hline Threshold 2 & & & & & .37 & $(1.8)$ & -1.5 & $(1.6)$ \\
\hline$R^{2}$ & \multicolumn{2}{|c|}{.11} & \multicolumn{2}{|c|}{.11} & \multicolumn{2}{|c|}{$\mathrm{F}_{(21,167)}=4.57$} & \multicolumn{2}{|c|}{$F_{(21,167)}=5.07$} \\
\hline$N$ & \multicolumn{2}{|c|}{1102} & \multicolumn{2}{|c|}{1102} & \multicolumn{2}{|c|}{537} & \multicolumn{2}{|c|}{537} \\
\hline
\end{tabular}

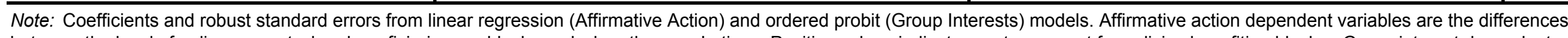

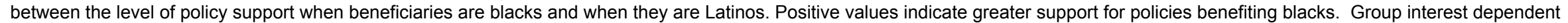

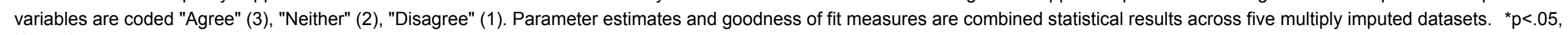
${ }^{* *} p<.01$ 

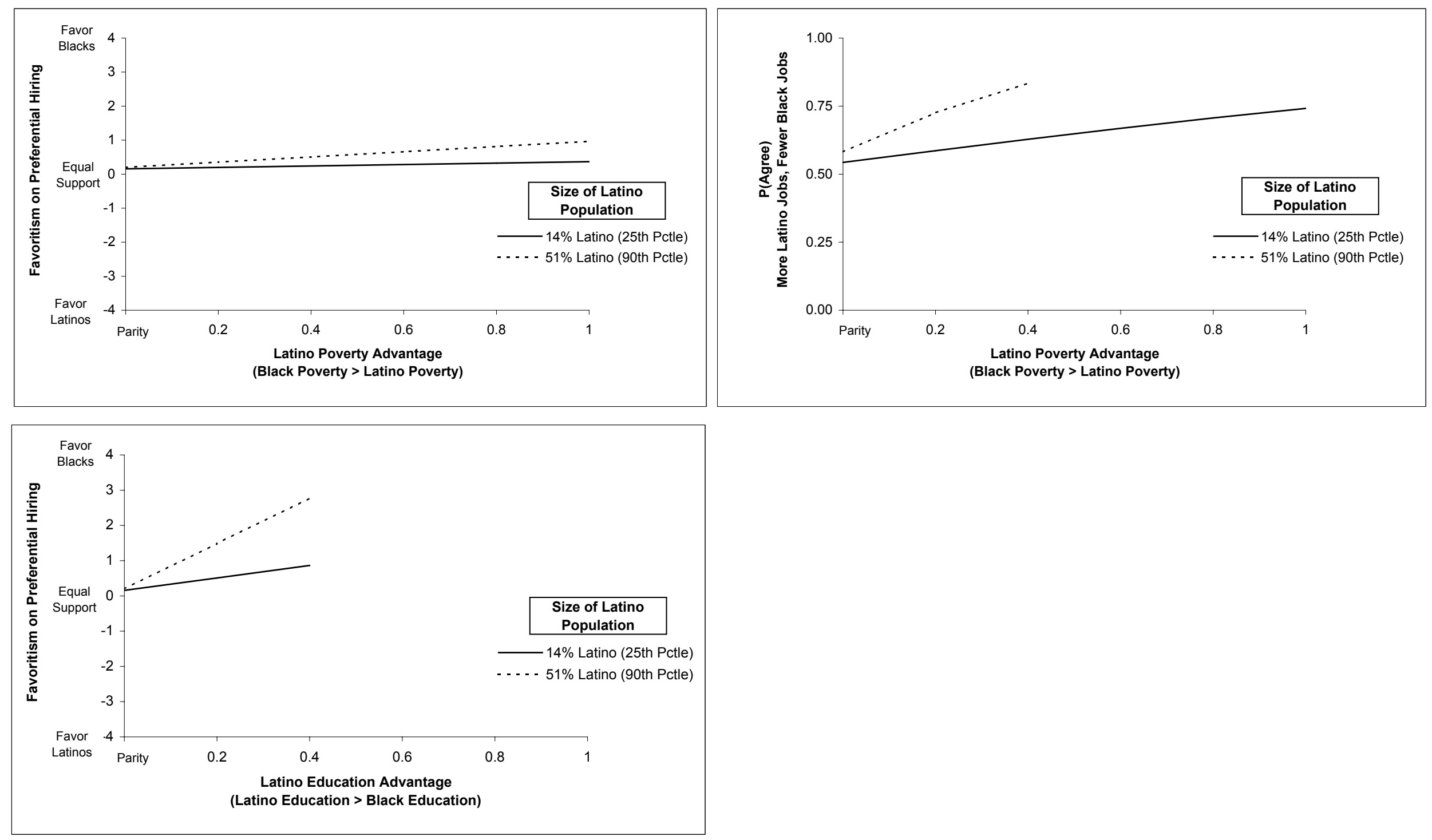

Note: Graphs depict the level of in-group favoritism on affirmative action (two left panels) and the probability of perceiving incompatible group interests (right panel) across levels of Latino economic advantage for two levels of percent Latino, holding all other independent variables constant at their means. Positive values on "Favoritism" graphs indicate greater support for preferences in hiring when the beneficiary is black rather than Latino. Values on "P(Agree)" graph indicate the probability respondent agrees with statement that "more good jobs for Latinos means fewer good jobs for Blacks." The predictions are derived from the linear regression and ordered probit estimates reported in Table 2. 